\title{
Serum C-reactive protein test in diagnosis of septic complications of cerebrospinal fluid shunts for hydrocephalus
}

\author{
R. BAYSTON \\ Children's Hospital, Sheffield
}

SUMMARY Serial tests for serum C-recctive protein (CRP) were carried out on 40 children undergoing cerebrospinal fluid shunt surgery, to determine the pattern of appearance and disappearance of CRP in relation to this type of operation, in the absence of postoperative complications. Samples of sera from a further 268 children, 79 of whom presented after shunt surgery with symptoms suggesting infective complications related to the shunt, were examined for CRP. The results showed that, while the test is negative in uncomplicated colonisation of ventriculo-atrial shunts, it is reliably positive in patients with colonised ventriculo-peritoneal shunts, ventriculitis, or shunt nephritis.

Tillet and Francis (1930) described a substance which was present in the sera of patients in the acute stage of pneumonia. Anderson and McCarty (1950) described the use of a capillary test for this Csubstance (now called C-reactive protein, CRP) in the serum to monitor the severity of the disease in rheumatic fever, and other workers used it to assess the presence and severity of other inflammatory conditions (Bunim et al., 1952). The exact nature and origin of CRP is still unclear. Immunological studies show that it is a globulin (Wood et al., 1954) but little is known about its site of origin, fate, or function (Wood, 1953; Kushner and Kaplan, 1961). CRP is an abnormal protein as it is not found in the serum of a healthy person, but appears in a matter of hours after onset of tissue damage or destruction, regardless of the cause, and disappears equally rapidly after the destructive process has ceased. CRP is not subject to normal variation, as is the erythrocyte sedimentation rate (ESR), and is independent of the haematocrit. In these respects it is generally found to be more useful and sensitive than the ESR as a reflection of acute inflammatory disease.

Sera from patients with cerebrospinal fluid (CSF) shunts were tested for presence of CRP to assess its usefulness as an adjunct to other diagnostic tests for septic complications associated with the use these devices.

Children's Hospital, Sheffield

R. BAYSTON, research fellow

\section{Patients and methods}

308 children admitted for insertion of a first shunt, revision of an existing one, or for investigation of possible shunt complications, were studied. Their ages ranged from 2 weeks to 15 years. All had hydrocephalus and, in many, this was associated with spina bifida. In others it was posthaemorrhagic, postmeningitic, or 'congenital'.

Blood was taken fromeach child preoperatively and then on days 5 and 10 postoperatively. A group of 40 of these children also had blood taken on the first day after operation. Samples were routinely taken from children at these times as a means of detecting shunt colonisation by the Staphylococcus albus antibody test (Bayston, 1972, 1975). Many were followed up as outpatients and further blood samples taken. In this hospital the Holter valve is used exclusively and both ventriculo-atrial and ventriculo-peritoneal routes are used.

Serum CRP was measured by the capillary method (Anderson and McCarty, 1950) using commercially prepared antiserum (Difco Laboratories Ltd). To perform the test, $25 \mu l$ of patient's serum are run into a capillary tube, followed by an equal volume of antiserum. The tube is rocked to and fro to mix, and one end is plunged into a block of modelling clay. The tube is kept upright in this manner at room temperature for 8 hours or overnight. If CRP is present a complex is formed which falls to the bottom of the column of fluid in the tube. The height of the column of precipitate is measured in millimetres to give a semi-quantitative result. 
Results

Of the 308 children studied, 229 did not develop any clinical abnormality or sign of shunt complications. 40 of these children had had CRP estimations carried out on samples taken on the day after operation, as well as preoperatively, and on the 5th and 10th postoperative days. 21 of these had insertion or revision of an atrial shunt, 17 had insertion or revision of a peritoneal shunt, and a further 2 had exploration of a peritoneal shunt limited to the distal end. The CRP results in these $\mathbf{4 0}$ children are shown in Table 1. All gave a positive test after the operation on day 1 , but by day 5 the test was negative except in the 17 children in whom insertion or full revision of a peritoneal shunt had been performed. All had become negative by day 10. In the remaining group of 189 patients who did not have CRP estimations carried out on the day after operation but in whom there were no complications, all had negative CRP tests preoperatively and on the 10th day postoperatively. Of the 87 patients in this group who had full revisions of peritoneal shunts, 79 had positive CRP tests on the 5th postoperative day.

The remaining 79 children subsequently presented, either at outpatient visit or on direct hospital admission, with one or more of the signs and symptoms of shunt colonisation. The results in these children, and their final diagnoses, are shown in Table 2. Shunt colonisation caused by Staphylococcus pyogenes gave rise to a positive test in all 7 patients. In 8 cases of ventriculitis and 8 of shunt nephritis the CRP test was uniformly positive. 11 cases of peritoneal shunt surgery showed a different pattern of results from those shown in Table 1 , in that the CRP test did not become negative by day 10 postoperatively, and was persistently positive when checked thereafter.

All 16 cases of uncomplicated atrial shunt colonisation due to $S$. albus, where there was no evidence of shunt nephritis or ventriculitis, gave negative CRP tests.

Table 1 Serum CRP results associated with shunt surgery in the absence of complications

\begin{tabular}{|c|c|c|c|c|}
\hline & \multicolumn{4}{|c|}{ Positive CRP } \\
\hline & \multirow{2}{*}{$\begin{array}{l}\text { Before } \\
\text { operation }\end{array}$} & \multicolumn{3}{|c|}{ After operation (days) } \\
\hline & & $I$ & 5 & 10 \\
\hline $\begin{array}{l}\text { Insertion or revision of } \\
\text { atrial shunt }(n=21) \\
\text { Insertion or revision of }\end{array}$ & $\mathbf{0}$ & 21 & $\mathbf{0}$ & 0 \\
\hline $\begin{array}{l}\text { peritoneal shunt }(n=17) \\
\text { Limited exploration of }\end{array}$ & $\mathbf{0}$ & 17 & 17 & $\mathbf{0}$ \\
\hline peritoneal shunt $(n=2)$ & 0 & 2 & 0 & $\mathbf{0}$ \\
\hline
\end{tabular}

Table 2 Serum CRP results and final diagnoses in 79 children with suspected shunt sepsis

\begin{tabular}{llll}
\hline Diagnostic group & $\begin{array}{l}\text { Positive } \\
(n=56)\end{array}$ & $\begin{array}{l}\text { Negative } \\
(n=23)\end{array}$ & $\begin{array}{l}\text { Subtotal } \\
(n=79)\end{array}$ \\
\hline Uncomplicated atrial shunt & & & \\
$\quad$ colonisation $(S$. albus $)$ & 0 & 16 & 16 \\
S. pyogenes shunt colonisation & 7 & 0 & 7 \\
Ventriculitis & 8 & 0 & 8 \\
Shunt nephritis & 8 & 0 & 8 \\
Colonised peritoneal shunt & 11 & 0 & 11 \\
$\quad$ (S. albus) & 2 & 0 & 2 \\
Intraventricular haemorrhage & 6 & 4 & 10 \\
Urinary tract infection & 9 & 3 & 12 \\
Respiratory tract infection & 5 & 0 & 5 \\
Otitis media & & & \\
\hline
\end{tabular}

The remaining 29 children in whom there was no evidence of sepsis of the shunt or central nervous system gave variable results.

\section{Discussion}

The CRP test has been used to monitor postoperative progress in general surgery (Fischer et al., 1976), and it has other applications, but its use in shunt surgery and its subsequent follow-up has not been described. The results of the test after shunt surgery in the absence of postoperative complications are shown in Table 1, and show that CRP is also present in the serum on day 1 postoperatively. If such operations are classified into three groups, the test will give negative results by day 5 in operations on atrial shunts; it was negative in the 2 patients in whom only limited exploration of the intraperitoneal portion of the shunt was carried out. However, in the 17 patients in whom a more extensive procedure was carried out (revision or insertion of a peritoneal shunt) the test was still positive on day 5 . The presence of CRP in the serum after shunt operation is presumably due to tissue damage incurred as a result of incision and dissection. To insert a catheter from the neck to the peritoneal cavity a tunnel has to be created over the rib cage with the use of much blunt dissection. This would explain the prolonged disappearance time for CRP in these cases.

In those 11 cases where the CRP test was persistently positive after operation, a diagnosis was made of colonisation of the shunt involving only the lower catheter. The children presented with signs suggesting blockage rather than colonisation (Bayston and Spitz, 1977) and the peritoneal reaction resulting from the flow of bacteria-laden CSF was found at operation to be causing partial obstruction of drainage. The reactive changes in the peritoneal cavity would explain the persistently positive CRP test.

The 7 cases of colonisation by $S$. pyogenes were 
all associated with postoperative infection of the scalp and/or neck wounds. Such colonisation is usually confined to the outer surface of the shunt, but because of the histolytic properties of the organism the infection rapidly tracks down the outside of the catheter and organisms enter the blood stream. There is considerable inflammatory response and it is therefore not surprising that the CRP test is positive in such cases.

However, in cases of colonisation of atrial shunts with $S$. albus, where the organisms are confined to the lumen of the shunt (Bayston and Penny, 1972) and enter the blood stream directly from the end of the distal catheter, there is no inflammatory response unless there is also involvement of the cerebral ventricles. In those uncomplicated cases without ventricular involvement, CRP is absent from the serum and diagnosis is confirmed by the finding of a positive $S$. albus antibody test.

Where the preoperative investigation of a patient includes a contrast or air ventriculogram, the finding of CRP in the serum the next day strongly suggests infective ventriculitis, and insertion of a shunt should be delayed until such infection has been ruled out, if possible by examining the ventricular fluid.

In a case of long-standing colonisation of atrial shunts, a positive CRP test often indicates the onset of shunt nephritis, even before haematuria is seen. At this stage the finding of high antibody levels to $S$. albus together with low serum complement levels confirms immune complex nephropathy.

The CRP test is nonspecific and positive results may be due to inflammation or tissue necrosis from any cause. Of 12 children whose symptoms were found to be due to a respiratory infection, 9 gave a positive CRP test. By subjective assessment, the illness in these patients was more severe than in the remaining 3. The 9 patients with positive CRP tests who had respiratory infections also had bacterial infections, whereas the remaining 3 were thought to have viral infections. Similarly the 5 cases of acute otitis media which showed a positive CRP test were found to be bacterial.

The test was also positive in 10 patients with urinary tract infection who presented with fever among their symptoms. Although precise details are not known, it is possible that those children with infection and ureteric reflux probably had renal involvement, and would be more likely to give a positive CRP test than those with cystitis alone.

As the purpose of this paper is to investigate the place of the CRP test in diagnosing septic complications of CSF shunts, the 22 children in whom CRP was found in the sera but in whom there was no involvement of the shunt may be thought of as false positives. However, if the test is found to be positive such possible causes as otitis media and infection of the respiratory and urinary tracts can be excluded easily and rapidly.

\section{Conclusions}

The results of the study suggest that the unexpected finding of CRP in the serum in a patient with a CSF shunt should always be vigorously investigated. The test is useful for detecting preoperative ventriculitis after ventriculography, and colonisation of ventriculo-peritoneal shunts. It is often the first indication of the onset of early shunt nephritis in those patients with long-standing colonised atrial shunts.

I thank the staff of the Paediatric Surgical Unit of the Children's Hospital, Sheffield, for their cooperation. The patients were under the care of Professor R. B. Zachary, Mr L. Spitz, and Dr J. Lorber. The work was supported by the Association for Spina Bifida and Hydrocephalus and the RICHARD Fund, Sheffield.

\section{References}

Anderson, H. C., and McCarty, M. (1950). Determination of C-reactive protein in blood as a measure of activity of disease process in acute rheumatic fever. American Journal of Medicine, 8, 445-455.

Bayston, R. (1972). Serological investigations in children with rolonised Spitz-Holter valves. Journal of Clinical Pathology, 25, 718-720.

Bayston, R. (1975). Serological surveillance of children with CSF shunting devices. Developmental Medicine and Child Neurology, 17, Supplement 35, 104-110.

Bayston, R., and Penny, S. R. (1972). Excessive production of mucoid substance in staphylococcus SIIA: a possible factor in colonisation of Holter shunts. Developmental Medicine and Child Neurology, 14, Supplement 27, 25-28.

Bayston, R., and Spitz, L. (1977). Infective and cystic causes of malfunction of ventriculoperitoneal shunts. Zeitschrift für Kinderchirurgie und Grenzgebiete, 22, 419-424.

Bunim, J. J., Kutner, A. G., Baldwin, J. S., and McEwen, C. (1952). Cortisone and corticotrophin in rheumatic fever and juvenile rheumatoid arthritis. Journal of the American Medical Association, 150, 1273-1278.

Fischer, C. L., Gill, C., Forrester, M. G., and Nakamura, R. (1976). Quantitation of 'acute phase proteins' postoperatively. Value in detection and monitoring of complications. American Journal of Clinical Pathology, 66, 840-846.

Kushner, I., and Kaplan, M. H. (1961). Studies of acute phase protein. I. An immuno-histochemical method for the localisation of Cx-reactive protein in rabbits: association with necrosis in inflammatory lesions. Journal of Experimental Medicine, 114, 961-974.

Tillet, W. S., and Francis, T., Jr (1930). Serological reactions in pneumonia with a non-protein somatic fraction of pneumococcus. Journal of Experimental Medicine, 52, 561-571. 
Wood, H. F. (1953). The relationship between the acutephase response and antibody production in the rabbit. I. Correlation between the early appearance of Cx-reactive protein and subsequent antibody production. Journal of Experimental Medicine, 98, 311-319.

Wood, H. F., McCarty, M., and Slater, R. J. (1954). The occurrence during acute infections of a protein not normally present in the blood. V. Physical-chemical properties

\section{Change of reference style}

From January 1980, the Archives will change its style for citing references and will follow the number system. We are making this change in order to conform with the 'Vancouver style' of uniform requirements for manuscripts submitted to biomedical journals.

Previously the Archives has used the Harvard reference system. Its advantages and disadvantages compared with those of the number system have seemed evenly balanced, but the editors have been aware of the burden imposed on authors and their secretaries by the different styles which different journals require. Therefore, with the unanimous agreement of the editorial committee, we have decided to support a move whereby a large - and increasing-number of major medical journals of the Cx-reactive protein crystallized by a modified technique. Journal of Experimental Medicine, 100, 71-79.

Correspondence to $\mathrm{Dr}$ R. Bayston, Children's Hospital, Western Bank, Sheffield S10 2TH.

Received 12 October 1978

will accept manuscripts presented in one agreed style.

The system numbers references consecutively in the order in which they are first mentioned in the text. References are identified in the text by arabic numerals. For further details see instructions to authors inside the front cover, and the references cited. ${ }^{1,2}$

From now onward all manuscripts submitted should accord with the new style.

1 International Steering Committee of Medical Editors. Uniform requirements for manuscripts submitted to biomedical journals. $\mathrm{Br}$ Med J 1979; 1; 533-535.

2 Lancet. The Vancouver style. Uniform requirements for manuscripts submitted to biomedical journals. Lancet $1979 ; 1 ; 429-430$. 